\title{
Feng-Shui Theory and Practice Investigated by Spatial Regression Modeling
}

\author{
Jung-Sup Um
}

Additional information is available at the end of the chapter

http://dx.doi.org/10.5772/47925

\section{Introduction}

Feng-Shui (meaning wind and water) has a strong indication for the placement of a physical object in space since it determines propitious locations by investigating the vital energy of the earth (Qi) throughout the lay of the land. Feng-Shui is the product of ancient Chinese cosmological beliefs and their responses to the land which were directly linked to survival and healthy living since it was believed that it could be used to harmonize people with their environment. Feng-Shui practices could be divided into landform Feng-Shui and livingspace Feng-Shui (Sung, 2001). Landform Feng-Shui practices have been conducted with emphasis on grave, residential sites, village, town, and city sites while living-space FengShui focused on the physical layout of such elements as the front gate, bedroom and kitchen. Today, living-space Feng-Shui is being widely used in the United States and Western Europe (Kim, 2003). In some respects, these two phenomena are quite different. However, they both involve patterns in siting that seem to express cosmological beliefs, numinous feelings and aesthetic experience.

Feng-Shui has been practiced in China and many other areas of Asia over the past five thousand years and it is becoming increasingly popular in western countries, such as the United States and Western Europe, thus gaining popularity world-wide (Chris, 2002; Diana 2004). Feng-shui theory and practice were based on considerable anecdotal evidence rather than on scientific proof. It should be noted that conflicts and debates exist when applying Feng-Shui rules because of the flexible practices and ambiguous literature (Andrew, 1968; Zetlin, 1995). Even Asians, who are familiar with ancient oriental literature and philosophy, have difficulty understanding the basic Feng-Shui concepts and methods of application.

So far the spatial variation of Feng-Shui locations is poorly defined despite abundant interest in this problem. Previous research for living space Feng-Shui has been based on the small number of in-situ observations reflecting the specific attributes of experimental sites 
such as the window, mirror and bed room (Hobson, 1994; Verlyn, 1995; Lu \& Jones, 2000). Field practices for living-space Feng-Shui have been researched with a focus on questionnaires (June, 2002). Field observations have the disadvantage that they provide only limited information on the area-wide distribution of the Feng-Shui locations.

Although area-wide data such as a topographic map for villages, towns and city sites in landform Feng-Shui have been used, it is rare to find enough experimental locations to prioritize the relative importance of spatial variables for Feng-Shui practice in those applications since just one sample used to occupy a huge area (e.g city site) (Hammond, 1995,; Xu, 1998; Zitao, 2000; Jun, 2003; Lynch, 2003; Mak \& Ng, 2005). Spatially prioritized parameters cannot, therefore, be adequately identified on the basis of such a few Feng-Shui locations. Until recently, the investigations of an area-wide distribution pattern of Feng-Shui locations and their spatial characteristics remained largely theoretical because the non-GIS survey technique had difficulty in assembling multi-thematic factors simultaneously (Earle, 1992). In the case of burial mounds, there is area-wide spatial evidence to document them. The actual grave distribution is a result of the complex interaction of historic and recent environmental and human factors. Tomb footprint shows a tenacious vision of what constitutes a proper mound location. The footprint of a grave characterizes Feng-Shui's spatial structure that varies with a multitude of factors such as the land use pattern and surface roughness. However, the field practices of tomb Feng-Shui have seldom been empirically examined in terms of area-wide spatial arrangements. It is necessary for the complicated belief system of Feng-Shui to be explained by describing how tomb footprint is distributed in space or with respect to each other. In Feng-Shui, every piece of information has to be looked at individually and put it together with others and look at the whole (or bigger) picture. Everything has its own place in every different situation and position. Concentrating on one point to the exclusion of all others does not lead to a balanced point of view. GIS is an ideal technology capable of integrating, merging and analyzing simultaneously multiple data layers to explore spatially prioritized relationships that are necessary when studying Feng-Shui footprints.

The multivariate spatial regression modeling compares multiple maps at one time and answers questions such as "how much more important is one map over the other". It is expected to reveal a consensus on how the Feng-Shui practice may have a universal sense of what is the most important variable for any place. If the importance or preference of each factor relative to other factors is identified in the context of a spatial multi-criteria framework, high priority areas in Feng-Shui will be identified. Therefore, the aim of this research was to evaluate major controlling factors in locating Feng-Shui tombs, using the spatial prioritization modelling techniques of GIS, based on the area-wide grave footprints in South Korea.

\section{General methodology}

\subsection{Model parameters}

Feng-Shui, by studying the configuration of mountains and rivers, selects a location where the vital energy (Qi) that flows throughout the earth is connected by water and not scattered 
by the wind. There is often a lack of understanding as to where this Qi is coming from. An important question is how to measure or represent criteria that are important to Feng-Shui practices and should be included in a spatial regression model. Preference variables perceived according to different cultures and geographical differences vary significantly across individuals and across the groups these individuals represent. Each grave location in a cluster, or isolated, takes into consideration the astrological conditions at the site for its unique occupant. It is important that the occupants of the sites are rich or poor, or what clans they represent. Facing a mountain at great distance is also considered as one of the important variables of a propitious location. The grave density is subject to complex, interacting influences, several of which, notably competition for favorable landscape and micro-site variability.

It is impossible to measure and quantify many of them for the purpose of spatial modeling since they need to be measured based on people's perceptions and feelings. It would clearly be impossible to model the behavior of every subjective variable involved in the burial decision. This method is extremely subjective since the model has to be run under vast numbers of combinations of rules, its approach is conceptually non-spatial. In such circumstances, there is no objective means of ascertaining the data quality and extent of the model. Such variables are too much subjective to be of great use in the modeling exercise.

Landform is frequently recognised as the most important factor in the grave location since it includes indicative information such as water features, vegetation, landslide susceptibility and soil moisture, etc. for the site investigated (Choi, 2001; Yoon 2006). Water moves through and over the landform, so the spatial distribution of soil and vegetation properties should be related to topographic attributes such as slope, elevation, and aspect and solar radiation in a specific grave location. The arrangement of meaningful Feng-Shui landscape "mountain in the back, water in the front" is closely related to landform factors such as the direction of maximum slope and transverse to the slope. In this regard, landform is believed to characterize changes in the flow of energy direction (Qi), flow velocity and Qi transport processes based on the orientation of mountains and spatial arrangements of topographic attributes such as slope.

In general, models of physical systems are forced to adopt aggregate approaches because of the enormous number of individual objects involved. It was necessary to focus on the variables which can be quantified to ensure the quality of the model, compared to the traditional use of subjective rules of thumb. These studies have employed only the most readily available and accessible data that are directly integrated with GIS to focus on representative and typical features in the experimental design and in order to evaluate the field Fung-Shui practices in an objective manner.

The main focus has been given to demonstrating the influence of the hillshade, elevation, slope and aspect as the most important factors controlling the spatial location of a grave. Landform multi-criteria models may provide an equitable and efficient means for exploring the spatial structure of Feng-Shui in terms of only stable physical geography. However, new grave location procedures could be influenced by various human factors 
beside landform parameters. In order for these tools to be effective, they should include criteria that are locally relevant and measurable in a human framework. To examine landuse effects and proximity to population on grave densities, several proximity variables calculated in accordance with the distance from roads were included as the model parameters (Table 2).

\subsection{Study area and data analysis}

Feng-Shui is responsible for many aspects of the cultural landscape in Korea, especially the location of tombs. The process of tomb location is extremely important in South Korea, since it is a common belief accepted by the Korean public that the location of the tomb would affect the descendant's well-being of the tomb's occupant. It is well known that a strong belief in Feng-Shui led kings in past dynasties to exhume and rebury their ancestors. "Even former and current presidents, and leaders of major political parties in South Korea, have moved their ancestors' graves or sought out propitious locations. Also, it was thought that burying one's parents in a place deemed propitious under Feng-Shui principles was a way to demonstrate filial piety (Kim, 2002)." The direction and position of grave were carefully selected by geomancers. "The spirit of Feng-Shui is still visible and strongly felt in the countryside, tightly integrated into the rural way of life" (Choi, 2001).

The burial areas are well maintained by a clan and memorial ceremonies are conducted on the traditional ancestor worship days such as Thanksgiving day and New Year's day, etc. at the tomb (Hough 1999). In this process, "Feng-Shui plays the role of a chain of life that connects an individual with his ancestors as well as descendants" (Yoon, 2006). "This is why Feng-Shui has continued to be influential despite being constantly criticized as a superstition (Kim 2002)". Such practices make the Korea the best place to explore the principles of Feng-Shui in the entire world.

The study area is situated in the south eastern part of South Korea between latitude $35.55^{\circ} \mathrm{N}$ and $36^{\circ} \mathrm{N}$ and longitude $128.38^{\circ} \mathrm{E}$ and $128.44^{\circ} \mathrm{E}$. It belongs to the Gongsan-Dong (administrative districts) in the city of Daegu, a metropolitan city recognized as the third most important city in South Korea, covering approximately $56.5 \mathrm{~km} 2$ (Fig. 1). It possesses several advantages that make it an appropriate choice for such a study. Its elevation ranges from approximately 60-834 $\mathrm{m}$ above sea level and shows a hilly character, frequently observed as the topography of typical grave locations in South Korea (1). The area is located on the south eastern edge of Palgong Mountain which is well known for geomantic ideals as well as one of the most spiritual mountains in the country. In Korea, Buddist monks appear as geomancer-monks who choose most of the auspicious places and thus the locations of many Buddhist temples have geomantic legends (Yoon, 1975). The study area was located in a place where it is easy to find many old temples in every valley and Buddhist heritages are scattered (Korean Heritage Online, 2006). The area is relatively isolated from the urban center, thus grave locations in the area still keep the appearance of the old dynasty period. The study area is located at the place where a cemetery is not available to investigate the natural location pattern of tombs by individual clans. 


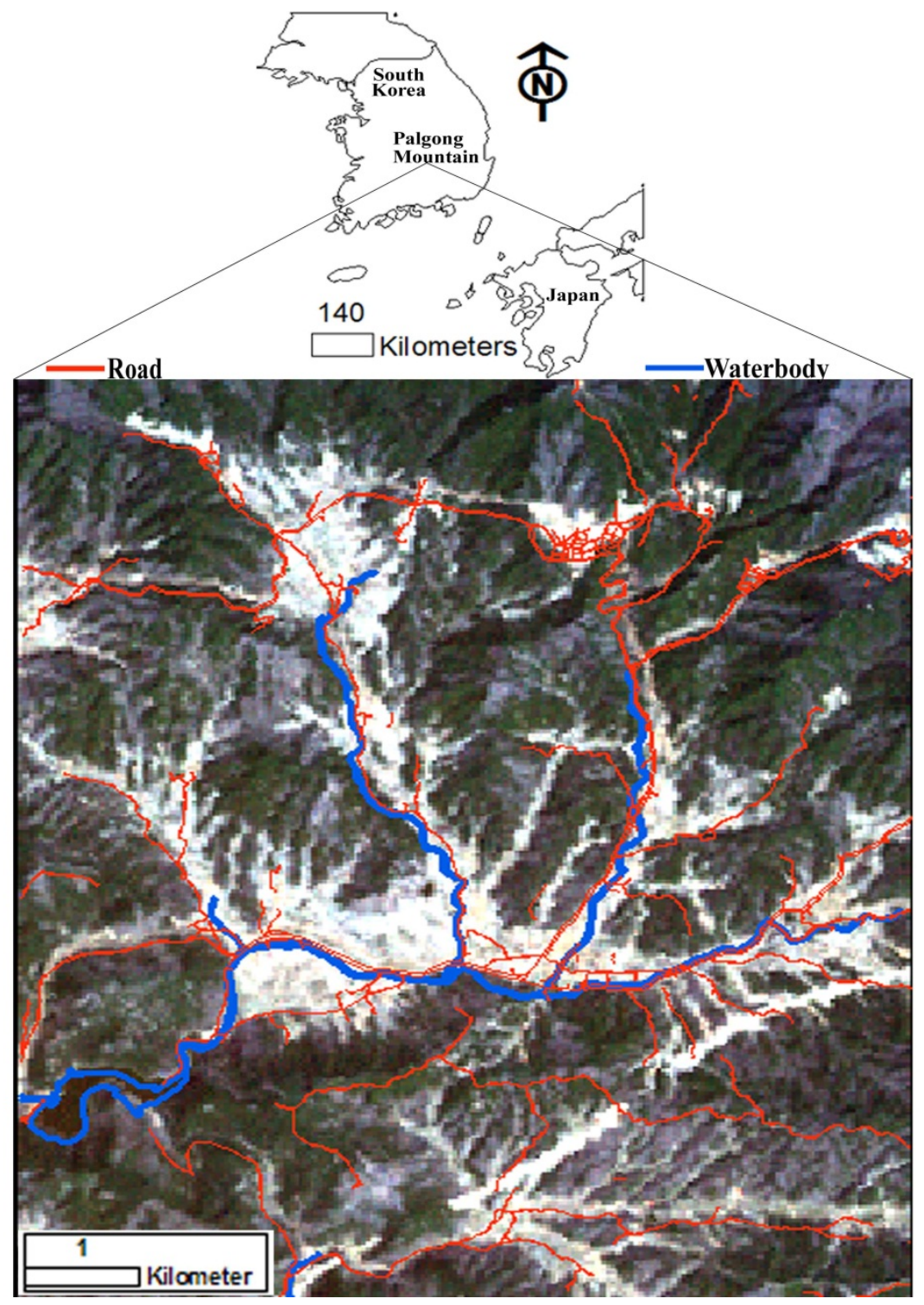

Figure 1. Location map of experimental site presented by a Thematic Mapper satellite image (acquired in April 2002) 


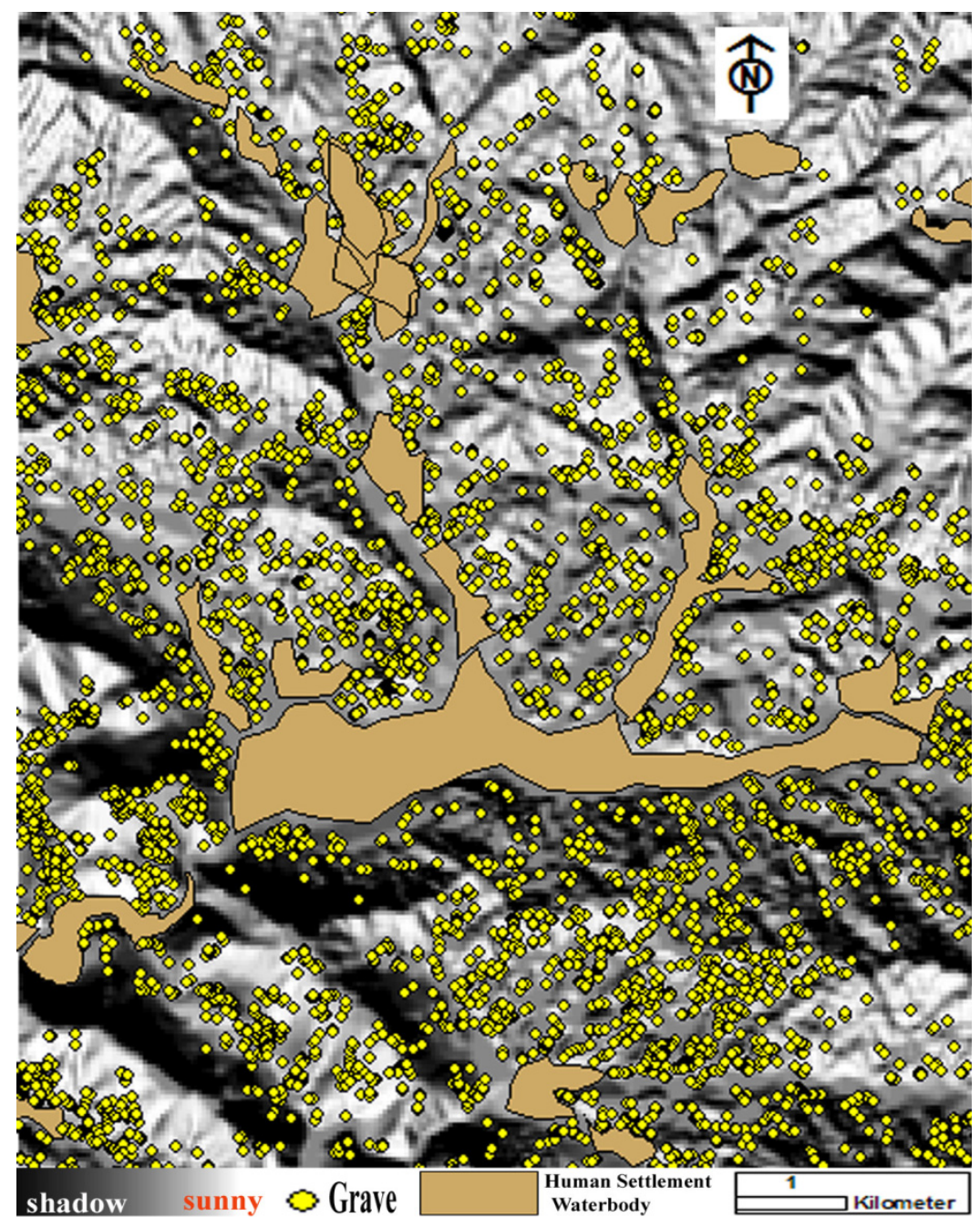

Figure 2. Solar radiation map combined with grave locations.

A shadow area at the south eastern end and northern part of the study area shows a very small number of graves.

A 1:5000 digital topographic map (produced in 1996 from aerial photography taken during the same year) was accessed via the national mapping authority of South Korea. The base map has been used to extract a Feng-Shui database such as the contour with $25 \mathrm{~m}$ equidistance, administrative boundary and road and tomb available in the study site. The human settlements, golf course and water-body have been excluded for further analysis since graves could not be located there (Fig. 2). The analysis in the ArcGIS was performed to identify and calculate spatial variables to be used in a regression model. A localized grave density map was created by defining the mean number of points per unit area in the ArcGIS 
to pinpoint spatially intensified distribution areas and examine the surrounding causal factors such as landforms. The search radius for the calculation of each pixel $(30 \mathrm{~m})$ was set to $300 \mathrm{~m}$ by an initial option suggested by the density slicing function of ArcGIS. The distributions of the concentration levels and predictor variables are presented by percentile scale as shown in the Fig. 2.

From the contours and spot heights, a DEM (Digital Elevation Model) was generated with pixel size $30 \mathrm{~m} \times 30 \mathrm{~m}$. Hillshade, slope and aspect layers were created as derivatives of the DEM. Computing the hillshade requires one to enter values that identify the sun's height and location in the sky. The hillshade grids were produced with an azimuth of 195 degrees, an altitude of 60 degrees based on the Korean holiday (Hansik) falling on the 105th day after the winter solstice (13:05 April 6, 1996) of the study site. It is a day for the family to move their ancestors' tombs and to hold their own memorial services. Each hillshade cell contains a value which indicates the sun intensity, ranging from 1 to 255 . It was used to determine what was in shadows and what was is in sunlight at that time in 1996.

The road-related spatial database, population density and land prices were already available for most areas of Korea. The population register (1996) was acquired from the Korean central statistical Office and land prices (1996) from the Korean Association of Property Appraisers (1996). The population and land price statistics were added to each administrative unit by means of joining the data table to a theme's attribute table. FengShui databases were built as integrated GIS layers and were overlaid accordingly. The data acquired from the spatial analysis were stored in MS Excel and basic statistical parameters were calculated to acquire the overall feature of the data sets. Multivariate spatial regression was undertaken by the SPSS statistical package to examine the relationships between grave concentrations and spatial variables potentially associated with grave density (Tables 2). The fit of the spatial models was assessed by the percentage of explained variation $\left(R^{2}\right)$, slope estimates of the parameters and their VIF (Variance Inflation Factor) were given.

\section{Result}

Summary data for the grave density in relation to proximity to roads is presented in Table 1 . The grave density data does not show a significant degree of variability for different proximity conditions from roads. The nearby places to the road are not more related than distant places in terms of grave concentration. Similarly the results of the regression analyses indicate that proximity to a road is not an important predictor of grave density. The population density did not make a significant contribution to explaining the variance in $\mathrm{R}^{2}$ since the owners of tombs are mostly residents of urbanized areas far away from the study area. The proximity or human variables were the least significant variables in the regression model. Furthermore, when the human variables were excluded, the $\mathrm{R}^{2}$ values for the models decreased by just 0.009 (0.754 to 0.745 ), showing the lower importance of road, population, and land price variables. By contrast, grave concentrations in landform parameters showed relatively high variability (Table 2 ). 


\begin{tabular}{|c|c|c|c|c|c|}
\hline $\begin{array}{c}\text { Road } \\
\text { (6 } \mathbf{~} \text { width) }\end{array}$ & density & $\begin{array}{c}\text { Road } \\
\text { (4m width) }\end{array}$ & density & $\begin{array}{c}\text { Road } \\
\text { (2 } \mathbf{~} \text { width) }\end{array}$ & density \\
\hline $\mathbf{5 0}$ (meter) & 84 & $\mathbf{5 0}$ (meter) & 83.9 & $\mathbf{5 0}$ (meter) & 78.9 \\
\hline $\mathbf{1 0 0}$ & 108.9 & $\mathbf{1 0 0}$ & 109.4 & $\mathbf{1 0 0}$ & 78.7 \\
\hline $\mathbf{2 0 0}$ & 118.8 & $\mathbf{2 0 0}$ & 124.6 & $\mathbf{2 0 0}$ & 76.6 \\
\hline $\mathbf{4 0 0}$ & 110.4 & $\mathbf{4 0 0}$ & 104.1 & $\mathbf{4 0 0}$ & 80.2 \\
\hline $\mathbf{6 0 0}$ & 83.6 & $\mathbf{6 0 0}$ & 102.4 & & \\
\hline $\mathbf{1 0 0 0}$ & 98.9 & $\mathbf{1 0 0 0}$ & 96.5 & & \\
\hline
\end{tabular}

Table 1. Area-wide grave density (number of graves per $\mathrm{km}^{2}$ ) in relation to buffer distance from road

\begin{tabular}{|c|c|c|c|c|c|c|}
\hline & \multicolumn{3}{|c|}{$\begin{array}{c}\text { Model } 1 \text { (with proximity and human } \\
\text { variables) }\end{array}$} & \multicolumn{3}{|c|}{$\begin{array}{c}\text { Model II } \\
\text { (with landform variables alone) }\end{array}$} \\
\hline $\begin{array}{l}\text { Summary of } \\
\text { model }\end{array}$ & \multicolumn{3}{|c|}{$\begin{array}{c}\text { Adjusted } \mathrm{R}^{2}=0.754, \text { number of } \\
\text { observations }(65523), \mathrm{F}=16719.154 \\
(\mathrm{P}=0.000)\end{array}$} & \multicolumn{3}{|c|}{$\begin{array}{c}\text { Adjusted } \mathrm{R}^{2}=0.745 \\
\text { number of observations } \\
(65523), \mathrm{F}=27405.752(\mathrm{P}=0.000)\end{array}$} \\
\hline $\begin{array}{l}\text { Explanatory } \\
\text { variables }\end{array}$ & $\begin{array}{l}\text { Standardized } \\
\text { coefficients }\end{array}$ & $\mathrm{t}$-value & $\begin{array}{c}\text { VIF } \\
\text { (Significance } \\
\text { levels }^{*} \text { ) }\end{array}$ & $\begin{array}{l}\text { Standardized } \\
\text { coefficients }\end{array}$ & $\mathrm{t}$-value & $\begin{array}{c}\text { VIF } \\
\text { (Significance } \\
\text { levels*) }^{*}\end{array}$ \\
\hline solar & 1.590 & 178.293 & 21.173 & 1.557 & 289.977 & 7.417 \\
\hline elevation & -.858 & \begin{tabular}{|c|}
- \\
148.941 \\
\end{tabular} & $8.832 \mathrm{z}$ & -.806 & \begin{tabular}{c|}
- \\
152.509 \\
\end{tabular} & 7.189 \\
\hline slope & -.191 & -34.111 & 8.329 & -.116 & -22.696 & 6.771 \\
\hline south & .049 & \begin{tabular}{|l|}
18.413 \\
\end{tabular} & 1.894 & .054 & 20.469 & 1.182 \\
\hline east & .063 & 23.922 & 1.818 & .069 & 26.662 & 1.746 \\
\hline west & .018 & 8.135 & 1.275 & .015 & 6.595 & 1.262 \\
\hline north & .001 & .472 & 1.101(.637) & -.002 & -1.145 & $\begin{array}{c}1.09 \\
(.252) \\
\end{array}$ \\
\hline $\operatorname{road}(6 \mathrm{~m})$ & .114 & 33.563 & 3.086 & & & \\
\hline $\operatorname{road}(4 \mathrm{~m})$ & .098 & 28.204 & 3.242 & & & \\
\hline $\operatorname{road}(2 \mathrm{~m})$ & -.003 & -.817 & $2.776(.414)$ & & & \\
\hline population & -.006 & .609 & $26.13(.543)$ & & & \\
\hline land price & -.080 & -8.695 & 22.36 & & & \\
\hline
\end{tabular}

* Significance levels are not presented in the case of $\mathrm{p}<0.001$.

Table 2. Multiple regression results including human variables and landform variables alone (dependent: grave density)

The $\mathrm{R}^{2}$ values for the models indicate that $74.5 \%$ of the variability of grave densities observed in the site was explained by the landform variables (Table 2). Initial observation of the grave map overlaid on the solar radiation clearly disclosed strong evidence for the influence of the sun index as a derivative of the integrated landform parameters at the grave distribution, as shown in Figs. 2-3. Solar illumination made the most significant contribution 
(b: 1.557) to explaining the variance in grave presence or absence (Fig. 2-3). Solar radiation is affected by various factors such as the latitude of the site investigated, slope and aspect of a site, sun's height and location in the sky. There was a more distinct preference for low altitude sites (Figs. 4-5) and a stronger association (b: -0.806) with decreasing elevation than those of slope (b: -0.116) and aspect. The relationship between the slope and the grave density variable is less distinct and a clear trend cannot be observed. A scatter plot shows that graves occur more frequently where the slope is intermediate (Fig. 6).

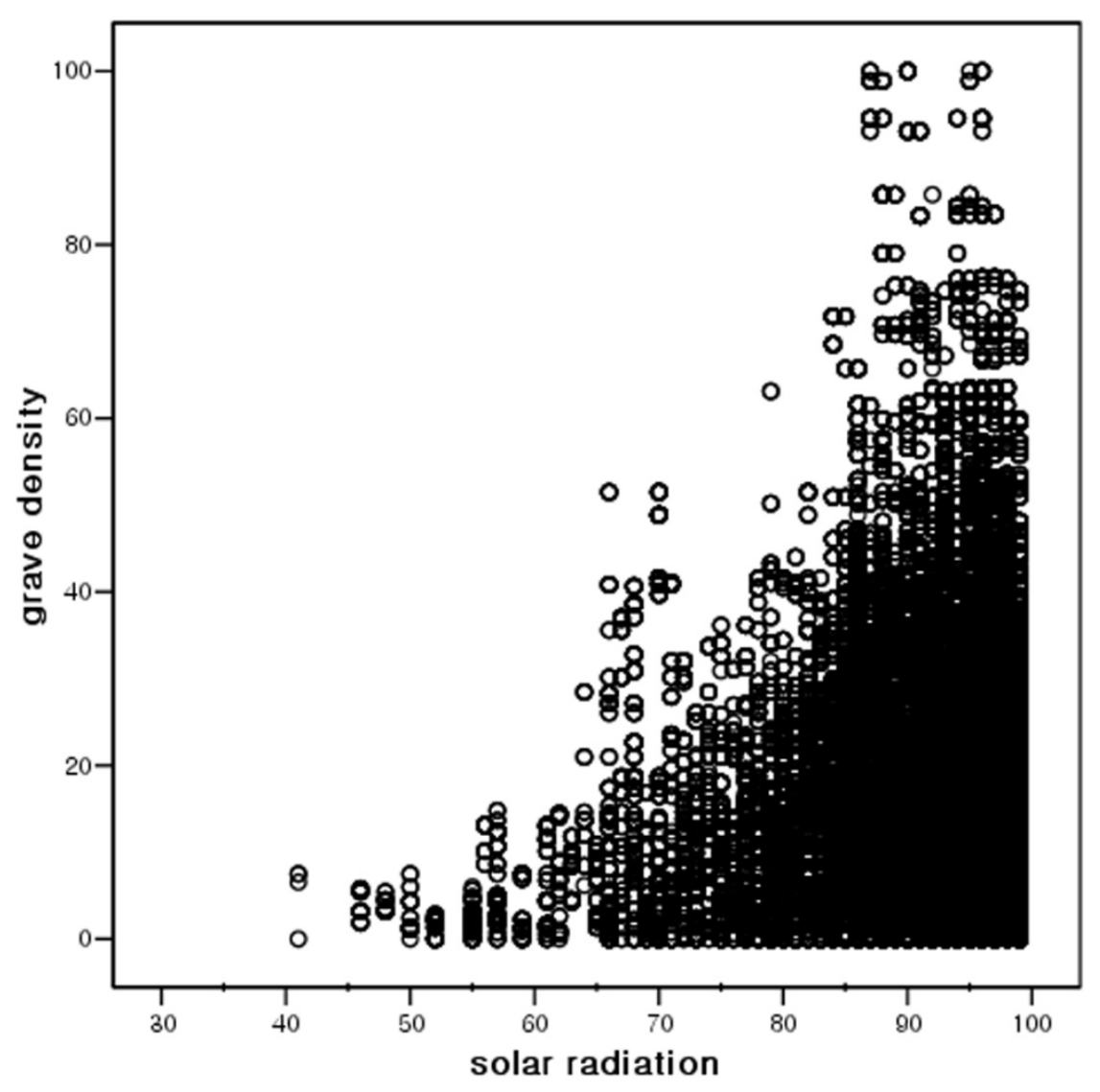

Figure 3. Plot of grave density vs. solar radiation (percentile scale, One hundred percent represents the highest grave density in the experimental site). Local grave density displays distinctively increasing trends in respect to the occurrence of a sunny site condition. The plot shows that the sun index is a crucial control factor on grave density. 


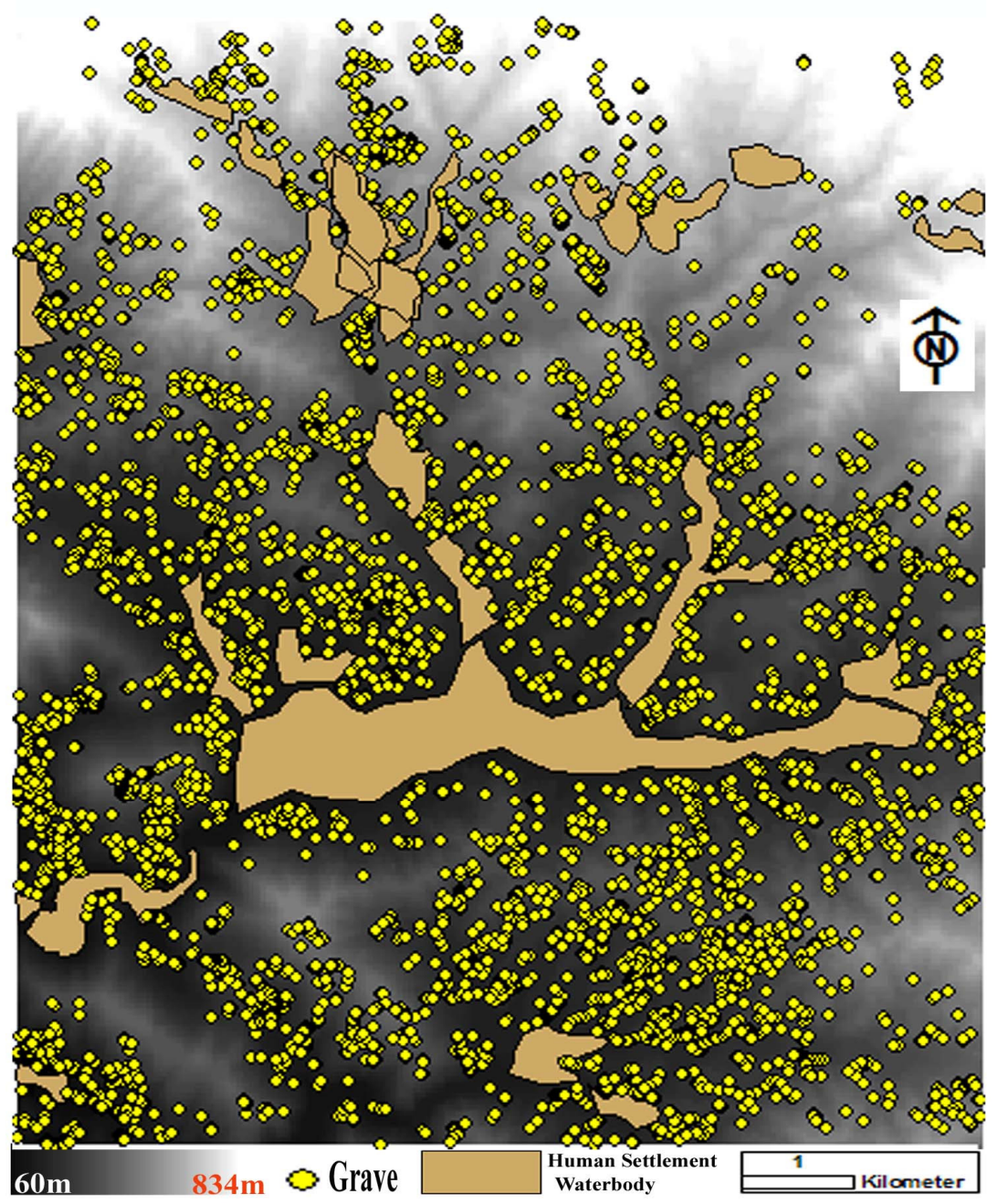

Figure 4. Digital Elevation Model combined with grave locations.

A highly elevated landform condition at the northern edge of the study area shows a very small number of graves. 


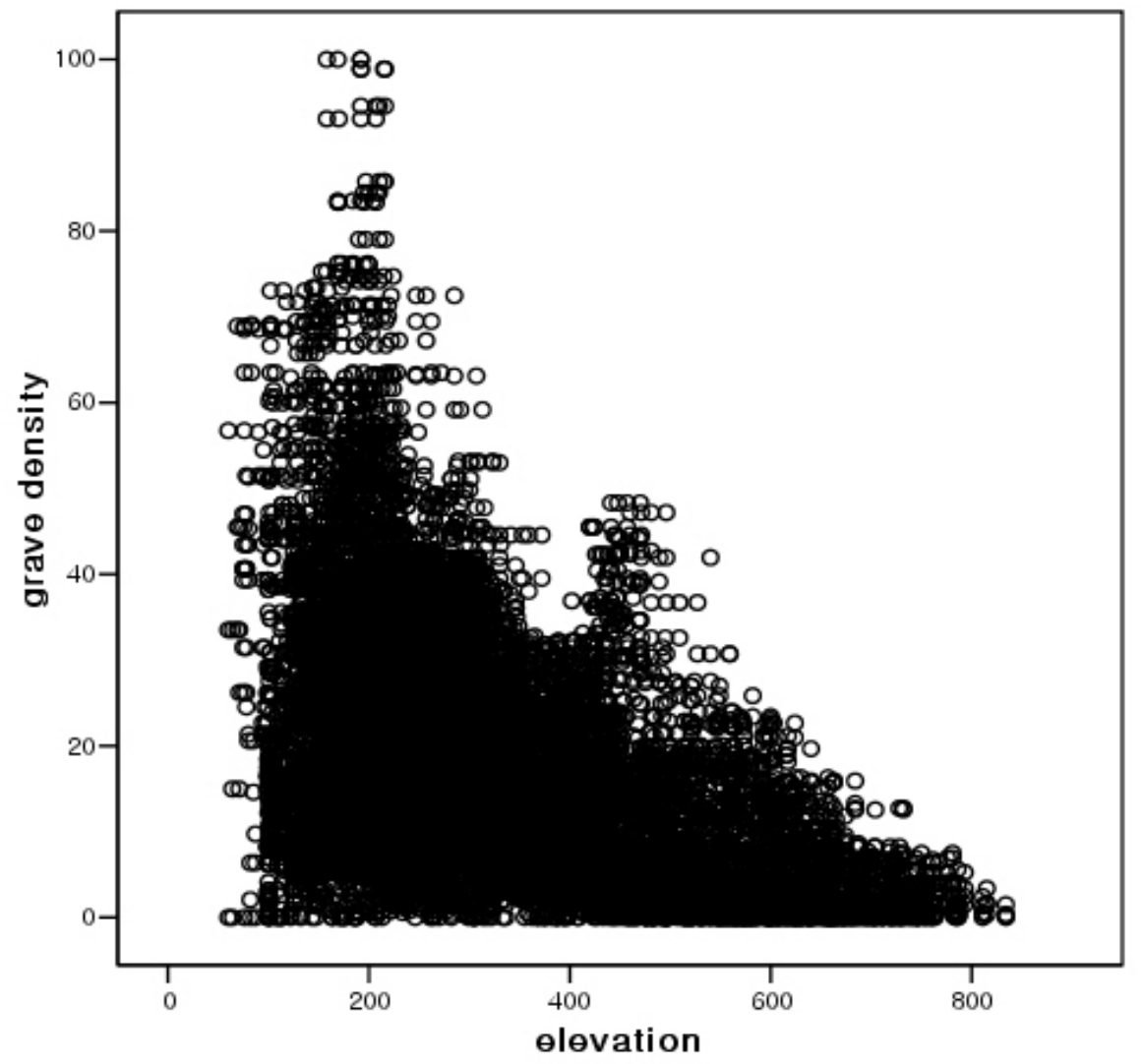

Figure 5. Plot of grave density (percentile scale) vs. elevation (m). Local grave density displays decreasing trends in respect to the occurrence of a high altitude condition. 


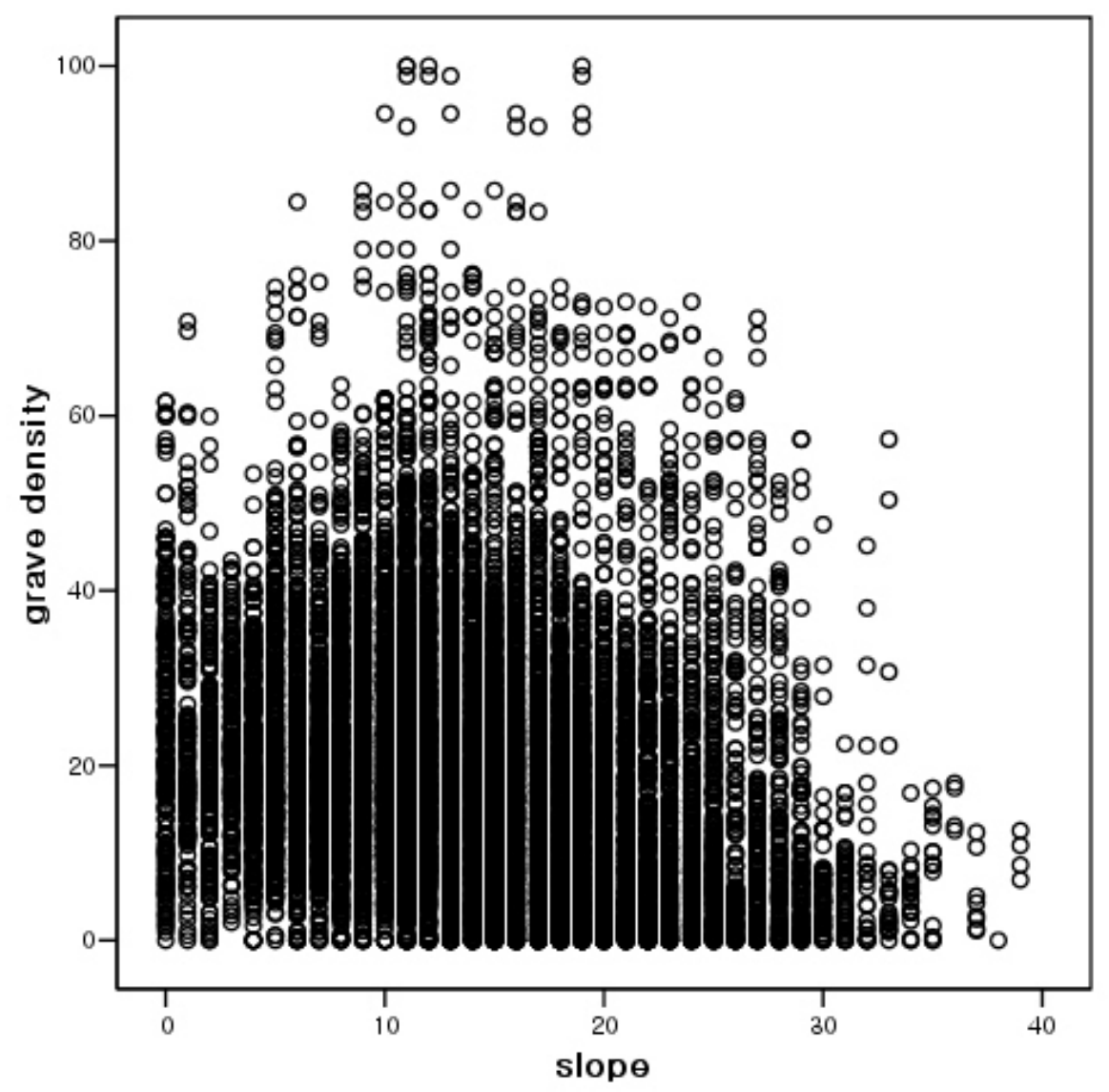

Figure 6. Plot of grave density (percentile scale) vs. slope $\left(^{\circ}\right)$. There is considerable scattering in the individual data points, but a higher grave density is generally found on the intermediate slope range. 


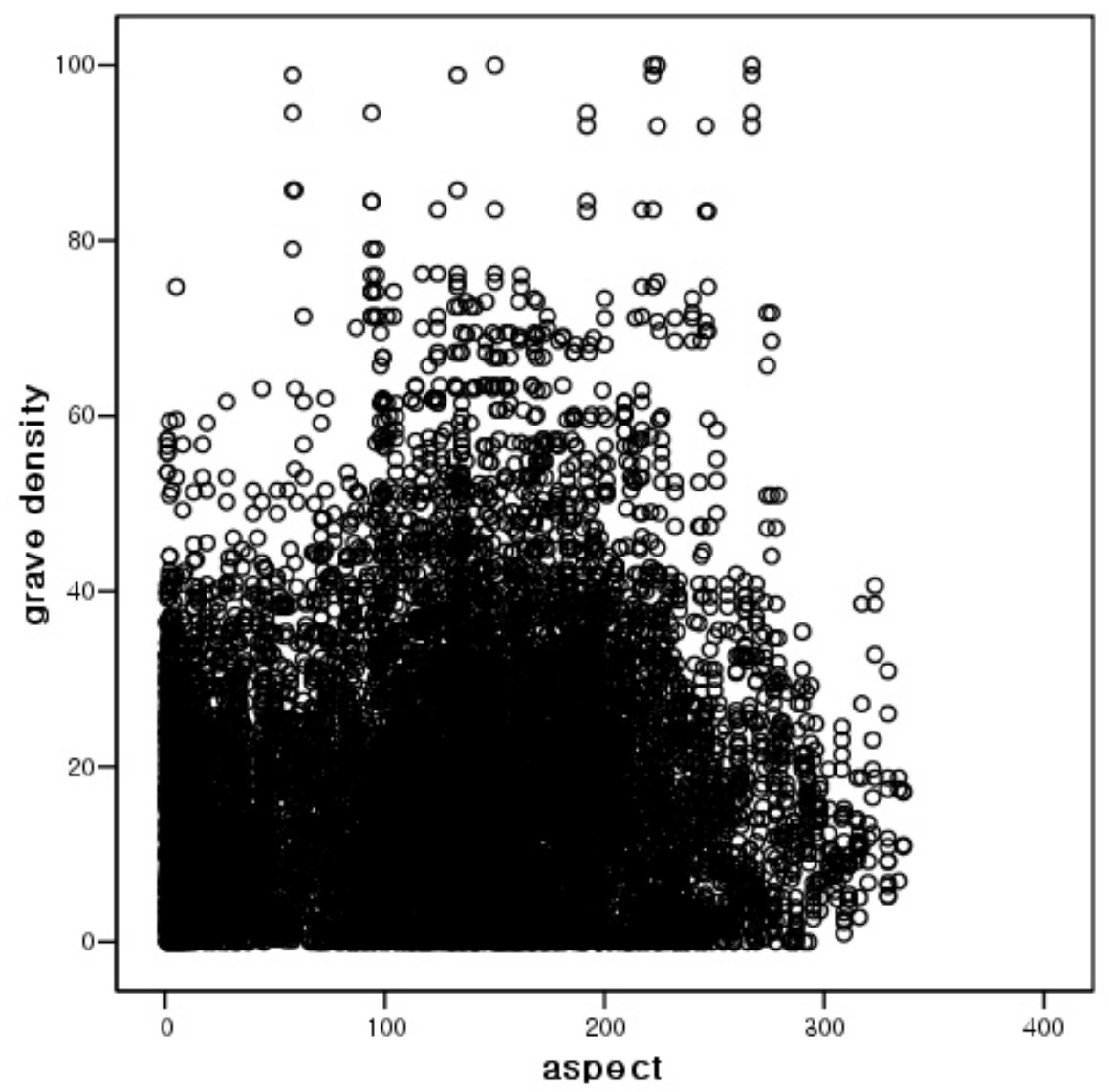

Figure 7. Plot of grave density (percentile scale) vs. aspect $\left({ }^{\circ}\right)$. Grave density is generally higher on south $\left(136^{\circ}-225^{\circ}\right)$ and east-facing $\left(46^{\circ}-135^{\circ}\right)$ slopes than on north $\left(0^{\circ}-45^{\circ}, 316^{\circ}-360^{\circ}\right)$ and west-facing slopes $\left(226^{\circ}-315^{\circ}\right)$.A distinct preference for south direction is not observed.

Grave density was generally higher on south and east-facing slopes than on north, and west-facing slopes (Table 2). The number of graves in the southern direction is not significantly higher than that of the east or west, different from the common belief that a south-facing is most favorable. The aspect parameter showed a much weaker influence (Fig. 7) on the grave distribution as a whole in the regression model than those of the sun's index (b: 1.557) and elevation (b: -0.806).

A comparison of scatter plots for the sun index with other landform variables indicated that grave density is much more abruptly decreased in a shadow condition than those with other explanatory variables such as elevation or slope. The sudden drop of grave density in accordance with the sun index bands indicates that the grave density is strongly associated to the site condition within the sun index 92 percentile. There were high joint effects for 
several variables, reflecting the colinearity between the variables. The most significant colinearity was among these three, the sun index 99 percentile, elevation $251 \mathrm{~m}$ and elevation $423 \mathrm{~m}$. Despite this colinearity, these variables were retained in the models because they could display their differing relative importance in the regression trees.

\section{Discussion}

Several studies have shown that Feng-Shui locations tend to be dependent on landform parameters, and increase if favorable conditions are observed, like when a site is located in low elevated hills, has a smooth slope and a good orientation facing south (Andrew, 1968; Yoon, 2006). The results of this study extend previous findings, specifically focused on the associations with the landform surface. The present study has utilized area-wide and pertinent information in the analysis of a Feng-Shui location to identify the spatially prioritized variables. In this project, the number of samples (5549) was large enough to extract reliable information relating to the existing state of the grave density in question, as substantial evidence of the spatially prioritized relationship caused by the Fung-Shui application. The area-wide grave data acquired from the topographic map produced by the interpretation of aerial photography provided sufficiently reliable information by replacing the questionable accuracy of a conventional field survey by a permanent record. This study has also demonstrated that a Geographic user friendly interface can be utilized for a factual assessment for Feng-Shui distribution by overcoming any serious subjective judgment suffered from the lack of a cartographic representation in the text based statistical data.

The spatial regression analysis allowed for assessing the level of consistency among the spatial variables in Feng-Shui practices by evaluating their stratifying hierarchy simultaneously. The grave locations were rarely affected by their degree of isolation or their degree of connectivity to roads, the dynamics of local populations and the price of the land segments. The results show that grave locations generally are determined only by the ideal Feng-Shui model established more than two thousand years ago without considering the surrounding environmental changes caused by urbanization. The spatial prioritization model clearly demonstrated that the sun index is perceived as extremely important while the elevation is considered moderately important and the aspect and slope are less important.

The actual importance (regression coefficient) value of the sun index presented by the spatial prioritization model can answer such a question as "how much more important is the sun index over the others?". In usual site selection cases, selecting one site over the other requires a tradeoff among spatial variables, provided the variables have a similar importance on site selection. The key issue in the spatial prioritization model would be a further tradeoff among first, the sun index, then the second most important and a combination of the rest. The magnitude of solar radiation and its relative importance is great enough to offset the difference in other landform parameters. It is believed that the FengShui experts used to take the most important factor, the sun index and make tradeoffs between the second important factor, elevation and the reduced combination set of the last two factors (slope and aspect). 
Feng-Shui emerged in the context of agricultural societies located in a temperate zone. It was essential to find a sunny location for farming and to survive in a chilly climate. In this regard, the relative merits of other landform factors in the overall Feng-Shui siting were very weak in comparison with the solar radiation in the spatial model. The sun index is much more influential a factor in the model's predictions since it is jointly determined by various landform parameters and the solar system in different locations. The findings of this study have important implications for the application of Feng-Shui and for future research. Also, the findings of this paper may assist in the more accurate targeting of Feng-Shui applications at their locations. It is believed that the postulates of the classical Feng-Shui theory are applicable to a specific sun light deficient area and not to the general case. In a tropical area, the sun can be quite intensive. It is not necessary for the sunlight to be shining into the sites all day (Tan, 2006). That is the reason why it is so hard to find real evidence of Feng-Shui applications in tropical regions such as South America and Africa.

This research has been carried out in one of the best country to explore the principles of Feng-Shui in the entire world. The experimental site is located on the site well known for geomantic ideals as well as one of the most spiritual mountains in the country. The spatial prioritization model derived in the study area may reflect Feng-Shui practices under ideal circumstances. The spatial dimensions of Feng-Shui locations vary according to the way different societies construct different shared cultural spaces. Moreover, the characteristics of the special case assumed by the classical Feng-Shui theory happen not to be those of the economic society in which we actually live. The perceptions about the surrounding environment generally vary with geographical differences. However, it is expected that the result of a Feng-Shui application will almost always parallel with the modern solar siting techniques and theories as the outcomes of these inspections have illustrated if the ancient Feng-Shui principles have been applied properly. Therefore the spatial prioritization model of this research will provide a standardized form against which to compare the real phenomenon of Feng-Shui. Although the cultural and geographical differences between the Western and Eastern Feng-Shui rarely behave this way, it is still useful to know what would happen if they did, as a basis for comparison.

\section{Conclusions}

Analyzing spatially prioritized parameters in relation to the Feng-Shui surface represents a critical step toward understanding how a local condition contributes to Feng-Shui landscape and will help to evaluate Feng-Shui locating strategies. This is one of a few studies that have looked at the relative importance of the differences of spatial variables within Feng-Shui locations and the first to formalize a solar illumination priority in a Feng-Shui tomb with area-wide empirical evidence. The spatial prioritization model showed that it could play a key role in evaluating Feng-Shui tomb distribution in which different kinds of landform mosaic mixes could be accommodated in the same location and could also occur in different locations. Therefore, this study made a valuable first step toward reducing its aura of superstitious mystery by investigating a major contribution factor for Feng-Shui locations through more rigorous and systematic approaches. 
Solar radiation was the most important predictor of grave density in the Feng-Shui locations. Similarly, spatial clustering technology identified the fact that high concentrations of grave necessarily accompany the significantly increasing trends of solar radiation. The results of the regression analyses indicate that the grave density could be explained by the four landform parameters alone yielding $\mathrm{R}^{2}$ values of 0.751 . In contrast to the typical theory, slope and aspect were not a dominant determining factor upon the dependent variable of grave density. Also, the significantly increasing trends of grave density were not observed in line with a southern direction. A clear verification has been made for the hidden assumptions in Feng-Shui 's long history that its approach is found to be more appropriate in avoiding shadow conditions, rather than exploring the ideal landform location

However, this research endeavor leaves many questions for further discussion and investigation. This study only finds statistically significant association between grave density and certain variables describing landscape and it does not attempt to elucidate what this association means in cultural terms with a more structured code of practice for Feng Shui application. One possibility is that dispersed patterns of graves could be the typical result of competition for a particularly auspicious piece of land. The presented approach to identify spatially prioritized parameters of Feng-Shui has yet to be tested in more diverse situations (agriculturally, environmentally and socio-economically) and the parameters of the analysis have to be more thoroughly validated through further research. This type of information generally requires extensive cross-cultural and comparative studies. There is a need to compare a variety of cultures equally from an objective viewpoint, to explore the spatially integrative relationship between the grave density and their surrounding landscape. This work constitutes an early step in the process of identification and characterization of the full suite of spatially prioritized parameters of Feng-Shui.

\section{Author details}

Jung-Sup Um

Kyungpook National University,

South Korea

\section{Acknowledgement}

Thanks are extended to the different national agencies of South Korea (Spatial Data Warehouse of National Geographic Information Institute, Central Statistical Office, Korean Association of Property Appraisers) for sharing their data for this project. I am grateful to Prof. Michael Goodchild of the National Science Foundation-funded National Center for Geographic Information and Analysis (NCGIA) at the University of California, Santa Barbara (UCSB) and Prof. Andrzej Weber, Department of Anthropology, University of Alberta, Canada for their critical remarks that helped in improving the manuscript. I would like to thank Shin Joon-Ho for the statistical advice and for the English corrections suggested by Paedar. 


\section{Notes}

This chapter was revised from the paper initially published in International Journal of Geographical Information Science (Taylor \& Francis), Vol. 23, No 3-4, March-April 2009, 513-529.

\section{References}

Andrew, L.M., (1968). An appreciation of Chinese geomancy. The Journal of Asian Studies, 2. pp. 253-267.

Carre, F. \& Giard M.C., (2002). Quantitative mapping of soil types based on regression kriging of taxonomic distances with landform and land cover attributes. Geoderma, 3-4, pp. 241-263.

Choi, W.S., (2001). A study of geomantic auxiliary temples and pagodas in the Yongnam region. Study of Korean History of Thought, 17, pp. 169-204.

Chris, T., (2002). The role of Feng-Shui: Haymarket priority project [Sydney, Australia] Landscape Australia 1, pp. 10-12.

Diana, L., (2004). California assemblyman proposes resolution that promotes building with Feng-Shui. Architectural Record, 4. pp. 48.

Earle, M.J., (1992). Spiritual landscapes: A comparative study of burial mound sites in the Upper Mississippi River Basin and the practice of' Feng-Shui' in East Asia. Ph.D Thesis, University of Minnesota, 270.

ESRI (Environmental System Research Institute), (2006). ArcGIS software help menu (spatial analysis toolbox).

Hammond, J., (1995). Ecological and cultural anatomy of Taishan villages. Modern Asian Studies, 3, pp. 555-572.

Hobson, J.S.P.1., (1994). Feng-Shui: its impacts on the Asian hospitality industry. International Journal of Contemporary Hospitality Management, 6, pp. 21-26.

Hough, W., (1999). Korean clan organization. American Anthropologist, 1, pp. 150-154.

Jun, X.A., (2003). Framework for site analysis with emphasis on Feng-Shui and contemporary environmental design principles. Ph.D Thesis, Virginia Polytechnic Institute and State University.

June, M.B., (2002). Feng-Shui: Implications of selected principles for holistic nursing care of the open heart patient. Master Thesis, University of South Africa.

Kim, D.G., (2002). Feng-Shui (Pungsu): chain of life that connects ancestors with descendants. Koreana, 4, pp. 24-31.

Korean Association of Property Appraisers, (2006). http://member.kapanet.co.kr/cgi-bin/gsv/ (accessed 10 February 2008).

Korean Heritage Online, (2006). Buddhist culture in Palgong Mountain, http://www.heritage.go.kr/eng/tou/tou_the_12_sce.jsp.(accessed 10 February 2008).

Lu, S.J. \& Jones, P.B., (2000). House design by surname in Feng-Shui Source. The Journal of Architecture, 4, pp. 355-367. 
Lunch, E. (2003). Feng-Shui as a site design tool: Assessing conditions of human comfort in urban places. Master Thesis, University of Arizona.

Mak M.Y.\& Ng.S.T., (2005). The art and science of Feng-Shui - a study on architects' perception. Building and Environment, 3, pp. 427-434.

Sung, D. H. (2001). Removing an illustrious imperial garden and the establishment of Hwasong according to Chongjo's view of geography and geomancy, Study of Korean History of Thought [South Korea] 17, 121-167.

Tan, M.L., (2006). Filipino 'feng shui'?

http://www.inq7.net/globalnation/col_pik/2003/aug14.htm (accessed 10 February 2008).

Verlyn, K., (1995). Bold illusion for California: unexpected ideas transform a San Jose tract house. Architectural Digest, 5, pp. 156-161.

Xu,P., (1998)."Feng-shui" models: structured traditional Beijing courtyard houses, Journal of Architectural and Planning Research, 4, pp. 271-282.

Yoon, H. K., (1975). An analysis of Korean geomancy tales. Asian Folklore Studies, 1, pp. 2134.

Yoon, H. K., (2006). The Nature and Culture of Feng-Shui in Korea.Lexington Book

Zetlin N, M., (1995). FENG-SHUI: Smart business or supersition? Management Review, 8, pp. 26

Zitao, F., (2000). Feng-Shui in site planning and design: A new perspective for sustainable development. Master Thesis, Arizona State University. 